\title{
Application of Fuzzy-TOPSIS Method in Supporting Supplier Selection with Focus on HSE Criteria: A Case Study in the Oil and Gas Industry
}

\author{
Assed N. Haddad ${ }^{1} *{ }^{\mathbb{D}}$, Bruno B. F. da Costa ${ }^{2} \mathbb{D}$, Larissa S. de Andrade ${ }^{1}$, Ahmed Hammad ${ }^{3}$ and Carlos A. P. Soares $^{4}{ }^{\mathbb{D}}$ \\ 1 Programa de Engenharia Ambiental, Universidade Federal do Rio de Janeiro, Rio de Janeiro 21941-901, Brazil; \\ larissa.sales@poli.ufrj.br \\ 2 Instituto Politécnico, Universidade Federal do Rio de Janeiro, Macaé 27930-560, Brazil; \\ bruno.barzellay@macae.ufrj.br \\ 3 UNSW Built Environment, University of New South Wales, Sydney 2052, Australia; a.hammad@unsw.edu.au \\ 4 Departamento de Engenharia Civil, Universidade Federal Fluminense, Niterói 24210-240, Brazil; \\ capsoares@id.uff.br \\ * Correspondence: assed@poli.ufrj.br
}

\section{check for}

updates

Citation: Haddad, A.N.; da Costa, B.B.F.; de Andrade, L.S.; Hammad, A.; Soares, C.A.P. Application of Fuzzy-TOPSIS Method in Supporting Supplier Selection with Focus on HSE Criteria: A Case Study in the Oil and Gas Industry. Infrastructures 2021, 6, 105. https://doi.org/10.3390/ infrastructures6080105

Academic Editor: Maxim

A. Dulebenets

Received: 10 July 2021

Accepted: 27 July 2021

Published: 28 July 2021

Publisher's Note: MDPI stays neutral with regard to jurisdictional claims in published maps and institutional affiliations.

Copyright: (c) 2021 by the authors. Licensee MDPI, Basel, Switzerland. This article is an open access article distributed under the terms and conditions of the Creative Commons Attribution (CC BY) license (https:/ / creativecommons.org/licenses/by/ $4.0 /)$.

\begin{abstract}
Supply chain management is an emerging topic in the oil and gas industry. There is higher exposure of contractors to undesirable incidents and supplier selection is a multicriteria decision problem (MCDM). A fuzzy-TOPSIS method was employed in the evaluation of three suppliers regarding four HSE criteria. This method was applied in a case study of the oil and gas industry involving a contractor bidding process. Results reinforced that fuzzy-TOPSIS is a versatile and suitable method for supplier selection problems, with low computational complexity and promoting a better user experience. This method contributes to greater effectiveness and agility in the selection processes of suppliers regarding HSE management. The fuzzy-TOPSIS model is suitable for supplier selection problems and some of the benefits of applying this method are that it allows the attribution weights according to the level of importance of each criterion and considers the complexity, subjectivity, and uncertainty of the decision process. One has determined that it was essential to have a robust and consistent process for weighting the criteria and defining the most appropriate linguistic variables.
\end{abstract}

Keywords: supplier selection; MCDM; fuzzy TOPSIS; HSE; fuzzy set theory; oil and gas industry; supply chain management; linguistic variables

\section{Introduction}

Since the early decades of the twentieth century, the oil and gas industry has mobilized several service networks and specialized segments which are part of the different levels of the industry's supply chain. The activities in this chain can be grouped into four major categories: exploration and production, transportation, refining and petrochemical industries, and distribution. The nature of the oil and gas industry's activities, which occupies a prominent position in the global energy sector [1], depends on a network of companies operating from exploration to distribution. This broad spectrum of action has favored the production chain process of sectorization and restructuring, especially in the offshore segment. Several factors have contributed to this predisposition, such as the variety of highly specialized activities and short-term operations. Such phenomena substantially influenced the increase in outsourcing and significantly boosted the participation of suppliers in the activities of this sector, transforming it into a complex socio-technical system [2].

In the context of various established working relationships, there is growing concern about the performance of these suppliers from a health, safety, and environment (HSE) standpoint and their potential exposure to high-risk activities. According to Smith [3], the changing of the workforce nature and the increasing involvement of contractors in 
the execution of high-risk activities and decision-making justifies the development of further studies on how working relationships established between client companies and contractors can influence better business HSE performance. Hiring qualified suppliers through the most efficient evaluation method and appropriate criteria is a key factor in ensuring that service providers are adequately trained and aligned with client HSE standards [4]. Such a process is crucial to the reliability of complex social-technical systems such as the offshore oil and gas industry, as those contractors and related subcontractors are often responsible for making decisions and performing controlling activities that lead to shut down a facility or facing system disturbances and other anomalies. Consequently, shaping a safer supply chain is highly relevant, as companies are held responsible not only for their actions but also for their partners' adverse impacts [5].

Although this is a relevant topic for the industry, supply chain HSE management is not yet a broadly addressed subject and is often treated as a subtopic of publications and studies related to general safety management [3]. Hollnagel et al. [6] outlined concepts on resilience engineering and introduced an initial approach to contractor safety management, promoting a debate about what is needed to control the associated HSE risk in a contractual environment effectively. Statistics of incident investigation worldwide have increasingly demonstrated that the number of accidents occurring in offshore oil and gas exploration and production activities has mostly involved third-party suppliers. It is also worth mentioning the occurrence of major process safety accidents in the global industry, such as the Deepwater Horizon disaster in the Gulf of Mexico in 2010, and more recently, the explosion at the São Mateus Cidade FPSO in Brazil, both involving one or more contractors, and leaving 11 and 9 dead, respectively.

Therefore, companies must have processes and systems for selecting, qualifying, managing, and influencing contractors concerning their capability to manage HSE aspects in contractual environments. Better contractor HSE performance can be achieved by integrating these aspects into the bidding process. The prequalification phase and the final selection of competent suppliers are key parts of the procurement process [7] and determine the success of all subsequent stages of the contractual relationship in a project. Supplier selection has been predominantly approached in the academic literature as a multicriteria decision problem based on economic aspects [8-10]. Therefore, cost should not be the only criterion to consider when selecting a contractor, as such a choice may impact project performance and the business in the long term [4]. Several papers can be found applying conventional criteria to the supplier selection process, such as: cost, management capacity, technical ability, financial integrity, quality, and innovation $[7,11]$. However, most of these studies have analyzed HSE aspects in light of a single criterion and merged with other operational and commercial criteria. This approach does not seem to be the most appropriate, since safety criteria when grouped with other types of parameters are often neglected, receiving less relevance in the decision of the experts responsible for the evaluation process. Thus, the main contribution of this work is the definition of criteria based exclusively on safety issues for supplier selection in the oil and gas industry, which were validated by the FTOPSIS method. The supplier selection process can become ambiguous as often the decision criteria are evaluated based on evidence provided by the contractors themselves, such as documentation, questionnaires, statistics, information on equipment availability, and personnel competence, which makes the evaluation process and comparison difficult and highly subjective during the selection phase [7]. In addition, it should be considered that for each judgment, different levels of importance, or weights, are assigned to the decision criteria, which are also influenced by subjective judgments. Thus, all these factors reflect a greater inaccuracy of numerical values attributed to each supplier's score concerning their performance. Therefore, the main motivation for this research was the proposition of tangible safety criteria to be applied in a structured way in supplier selection problems, especially in the oil and gas industry.

As a multicriteria decision-making (MCDM) problem, different methods may be applied to supplier selection. The use of multi-attribute methods has been approached 
by several authors, who have explored their application in isolation or by combining techniques to solve this kind of problem. Usually, at least two techniques are used together, one to estimate the weights of each criterion, and another to select the most suitable supplier, through the ranking of available options. However, in cases wherein the number of experts is limited, such as in this case study, the use of weights for each criterion becomes less representative. In this paper, the relevance of each criterion in the final classification is given according to its relationship with the degree of risk involved in the activity. This is a different approach from the one used in previously published models, but it is pertinent to cases where safety criteria take precedence. Furthermore, although there is extensive literature on the subject, to the best of the author's knowledge, this is the first study to use fuzzy TOPSIS to select suppliers in the oil and gas industry solely based on safety criteria. The selection of qualified contractors is a critical step for the success of oil and gas companies' projects and operations. A robust selection process, considering appropriate criteria, enables greater reliability to this choice. However, such a decision should be costdriven and influenced by non-economic criteria in this assessment [4]. The HSE aspects are examples of non-economic criteria, which have been receiving increasing attention from companies to avoid accidents due to financial and reputational losses for the business.

The main objective of this study is to identify the HSE criteria for safety supplier selection in the oil and gas industry. The selected criteria were validated through a case study where a fuzzy-TOPSIS model was applied to select a supplier for an operations and maintenance $(\mathrm{O} \& \mathrm{M})$ contract of a floating production storage and offloading (FPSO), with a focus on HSE aspects for supplier prioritization. Although several advanced MCDM methods have been developed in the last decades to deal with supplier selection problems, FTOPSIS has been used by several authors in case studies in the most diverse industries, such as automotive, petrochemical, energy, electronics, and logistics. The simple and flexible nature of the method [9] motivated its use in this work, given the small number of specialists employed, thus ensuring fast and accurate information processing. Through this study, it will be possible to guide oil and gas professionals and other industries with the application of MCDM methods in selecting suppliers concerning HSE management.

The remainder of this paper is structured as follows: Section 2 presents the conceptual background of the research, based on a review of the previous studies on multicriteria decision-making methods applied to supplier selection problems. Section 3 describes the fuzzy-TOPSIS approach and the linguistic variables and criteria employed in this study. Section 4 presents a numerical case to verify the proposed model and the research findings. Finally, Section 5 discusses study implications, summarizes the conclusions, and exposes work limitations and directions for further research.

\section{Literature Review}

The concept of supply chain management (SCM) was developed in the 1980s [12]. In recent years, researchers have widely explored the overall performance of the production chain by selecting the best possible supplier for a given product or service [11,13]. Suppliers are crucial partners and play a strategic role in any organization, as their activities directly affect the contractor's competitive capacity and profitability $[9,10]$. Therefore, the decisionmaking process applied to the selection of suitable suppliers, based on the evaluation of their performance, is one of the most critical and substantial tasks of the SCM field and should be based on the choice of representative and relevant criteria [14,15].

Choosing the best criteria and determining their respective weights is fundamental as it establishes the basis for a fair and reliable analysis of suppliers and considerably affects the ranking of alternatives [16]. However, it is not always possible to establish precise numerical metrics to this end $[5,17]$. Thus, linguistic variables such as "good," "average," or "poor" are often used by decision-makers (DM) to express their opinions [17,18]. Despite constituting a more organic form of judgment that respects human cognitive limitations, the use of linguistic terms is associated with a high level of uncertainty, given the subjective and imprecise characteristic inherent in the understanding of each DM [19,20]. Traditional 
methods based only on the simple evaluation of suppliers through the experience of referees or on trial-and-error strategies are not efficient, given the growing complexity of operations [21]. Thereby, the use of decision-making models that mitigate the effects of this vagueness is more likely to obtain realistic results than deterministic models [11].

Supplier selection is a typical problem of high-complexity multicriteria decisionmaking (MCDM) $[4,8,22]$, which is a very useful tool to identify the most suitable alternative where a limited number of suppliers are evaluated against a group of often conflicting criteria $[9,23]$. MCDM models combine qualitative techniques, which are highly dependent on the opinion of the DMs and which, by their nature, are not measurable, with quantitative procedures that depend on a mathematical approach and are based mainly on data $[19,21]$. In the last decade, distinct MCDM techniques have been proposed to allow the consideration of multiple criteria and alternatives at the same time [24-26]. Each one has its advantages and limitations [11], strongly depending on the studied business context [27]. Thus, the option for the best method to be applied is directly related to the complexity and type of problem in question, making it impossible to define a single model that meets all situations [28].

Among the different MCDM techniques employed to solve the supplier selection problem, some of the most applied are the analytic hierarchy process (AHP), the analytic network process (ANP), the technique for order of preference by similarity to ideal solution (TOPSIS), the VIseKriterijumska Optimizacija I Kompromisno Resenje (VIKOR), preference ranking organization method for enrichment evaluations (PROMOTHEE), the decision-making trial and evaluation laboratory (DEMATEL), and the best-worst method (BWM) $[4,11,16,21,29-33]$. A new generation of MCDM techniques has been developed in recent decades and has also been successfully applied to solve supplier selection problems, such as the simultaneous evaluation of criteria and alternatives (SECA) [34], the weighted aggregated sum product assessment (WASPAS) [35,36], the evaluation based on distance from average solution (EDAS) [37,38], the pivot pairwise relative criteria importance assessment (PIPRECIA) [39], the additive ratio assessment (ARAS) [40,41], the weighted implementation of suboptimal paths (WISP) [42] and the MULTIMOOSRAL method [43]. Some authors have also proposed the application of hybrid models, which are combined MCDM techniques, to mitigate the weaknesses presented by them when used in isolation, such as AHP and VIKOR [26], ANP and TOPSIS [44], AHP and TOPSIS [45], and AHP and DEA [46].

Considering the methods mentioned above, TOPSIS has been most frequently employed to select suppliers [47-49]. It may be due to the fact that in the literature many authors consider it more quick, flexible, understandable, and simple than other MCDM techniques [9,50]. However, despite being widely used, the traditional TOPSIS presents some limitations [51]. The main one is related to the use of crisp numbers that are normally not efficient in representing the subjective nature of human thought $[4,19]$, which, in real situations, may cause the method not to accurately reflect DMs' preferences [12,51]. Therefore, according to Li et al. [50], traditional TOPSIS cannot handle vagueness or ambiguous information from expert evaluations. To overcome this deficiency, several studies have implemented fuzzy logic concepts along with MCDM techniques to solve problems in the supplier selection field and what has been called fuzzy multicriteria decision-making (FMCDM) [4,9,10,12,19,33,50,52].

The fuzzy set theory (FST) was first proposed by Zadeh [53]. The methodology was based on the principle that human thought is always fuzzy and generally imprecise when selecting an alternative among others with different levels of relevance [9]. Since then, it has been used in combination with various methods to solve complex problems, allowing for the reduction of uncertainties inherent in the subjective judgment of experts $[12,29,54,55]$. FST applies linguistic variables rather than precise values, improving evaluators' communication and increasing the accuracy of results [56]. Thus, the fuzzy TOPSIS method (FTOPSIS) has been widely used in supplier selection problems, alone or integrated with other techniques [50]. 
There are some notable studies in the literature using FTOPSIS in supplier selection. Memari et al. [9] employed FTOPSIS to evaluate sustainable suppliers for an automotive manufacturer. Sahin et al. [55] applied FTOPSIS to classify multiple suppliers in the context of shipping investment. Mina et al. [4] used fuzzy AHP and fuzzy TOPSIS methods to evaluate and rank petrochemical industry suppliers in the circular supply chain. A similar strategy was presented by Chatterjee and Stevic [57], who used fuzzy AHP to determine criteria weights and fuzzy TOPSIS to rank potential suppliers in a manufacturing organization. Li et al. [50] proposed an extended TOPSIS method for sustainable supplier selection in a Chinese energy company. Tirkolaee et al. [49] integrated fuzzy ANP, fuzzy DEMATEL, and fuzzy TOPSIS to maximize the supply chain's reliability. Rashidi and Cullinane [29] selected sustainable suppliers for a logistic industry in Sweden, comparing results from fuzzy DEA and fuzzy TOPSIS. Chen et al. [30] developed a hybrid rough-fuzzy DEMATEL-TOPSIS for supplier selection in a smart supply chain. FTOPSIS was used by Hasan et al. [58] to rank resilient suppliers in the logistic 4.0 industry. Kilic and Yalcin [51] proposed an integrated methodology with TOPSIS strategy for supplier evaluation in the air filter industry in an intuitionistic fuzzy environment. Javad et al. [59] first applied the BWM method to explore different criteria of green supplier selection, while FTOPSIS was employed to rank the considered suppliers based on their green innovation ability in a steel company. A hybrid MCDM approach was developed by Yucesan et al. [60] to identify green suppliers in a plastic facility in Turkey using BWM and FTOPSIS methods. Kannan et al. [61] selected green suppliers for a Brazilian electronics company using FTOPSIS to rank the 12 available suppliers. Çalik [62] presented a real case study on an agricultural tools and machine company, integrating AHP and TOPSIS under the Pythagorean fuzzy environment to select the best green supplier. Finally, Banaeian et al. [63] incorporated fuzzy theory into TOPSIS, VIKOR, and gray relational analysis (GRA) to select a green supplier for an agri-food company, comparing the results between the methods.

Given the literature review, the following objectives are identified for the hypothetical case study presented:

- Identify the HSE criteria for safety supplier selection in the oil and gas industry;

- Estimate weights for the HSE criteria through a risk matrix; and

- $\quad$ Select the most suitable supplier using the fuzzy TOPSIS method.

\section{Materials and Methods}

\subsection{Fuzzy-TOPSIS Method}

TOPSIS is an MCDM method developed by Hwang and Yoon [64], which is based on the principle of "relative closeness to an ideal solution" [19]. In other words, the main objective is to find an optimal solution from several alternatives that should be as close as possible to the positive ideal solution (PIS), and as far as possible from the negative ideal solution (NIS) $[11,19,20,65]$. In this technique, after defining the weights for each predetermined criterion, the scores are calculated, normalized, and then the geometric distance of each alternative to the PIS and NIS is computed [55]. The best alternative is then selected through the closeness coefficient, which can be considered a composite classification index, indicating the option with the greatest similarity to the ideal solution $[4,33]$.

In the classic TOPSIS approach, as mentioned before, the input information that composes the decision matrix must be numeric and well defined [33]. Despite being an easy understanding method, its application in isolation proves to be inefficient in solving supplier selection problems since it is not able to handle uncertainty [12]. Nevertheless, the TOPSIS method can be adapted to deal with the vagueness of the assessment information through its integration with fuzzy logic [4,12]. Fuzzy TOPSIS combines traditional TOPSIS with the fuzzy set theory, where weights are defined as linguistic terms and then converted to fuzzy numbers [4]. It is defined as a multicriteria decision-making tool, the process of which is illustrated in Figure 1. 


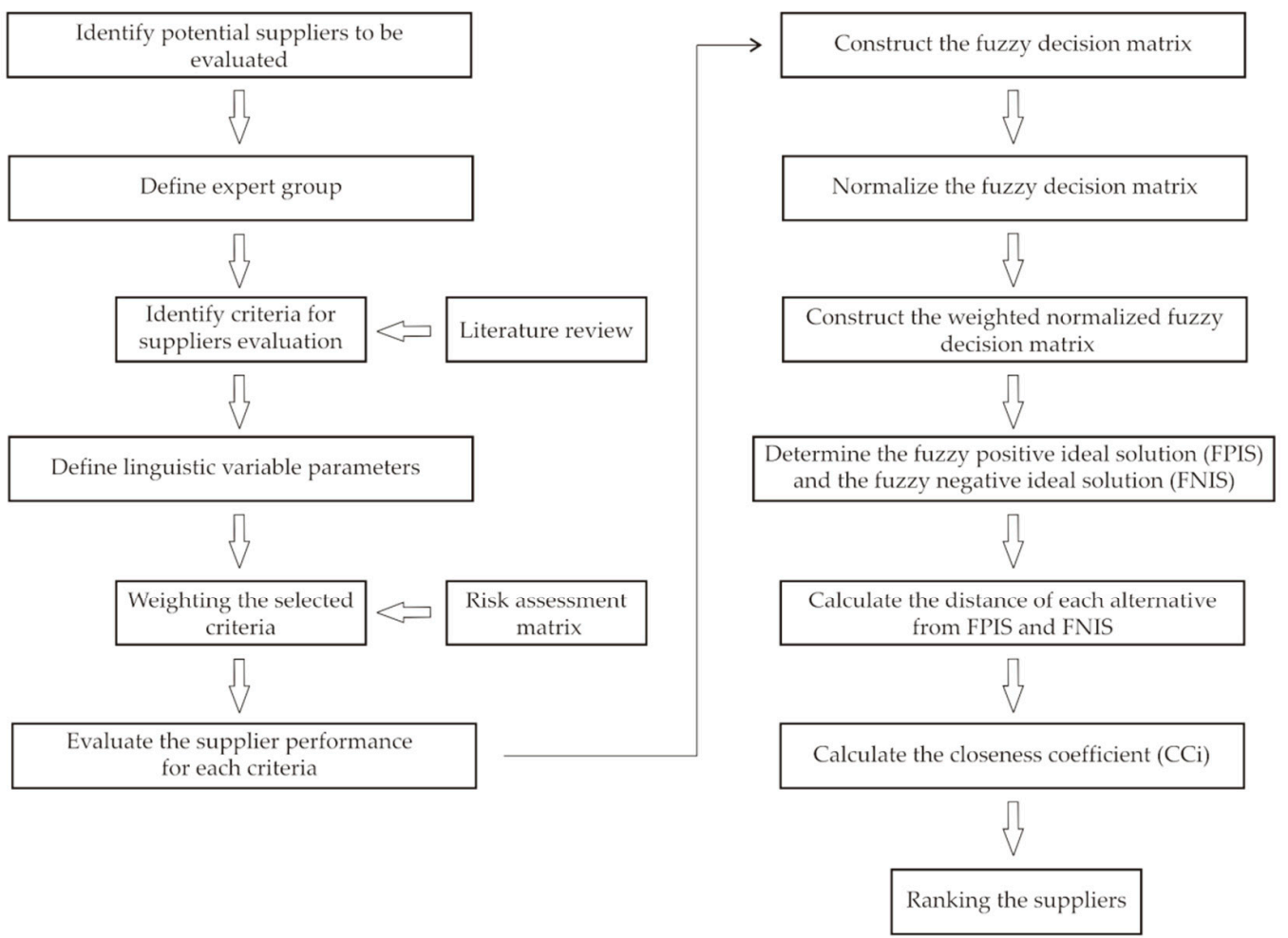

Figure 1. Framework of the proposed MCDM supplier selection model.

After assigning weights to criteria using linguistic variables and generating decision matrices composed of fuzzy numbers defined in the interval $(0,1)$, fuzzy TOPSIS is formulated in the following steps:

Step 1: construction of the normalized fuzzy decision matrix

Considering $R$ as the normalized fuzzy decision matrix:

$$
R=\left[r_{i j}\right]_{m * n^{\prime}} \quad i=1,2, \ldots, m ; \quad j=1,2, \ldots, n
$$

The normalized values for benefit and cost criteria are:

$$
\begin{aligned}
r_{i j} & =\left(\frac{a_{i j}}{c_{j}^{+}}, \frac{b_{i j}}{c_{j}^{+}}, \frac{c_{i j}}{c_{j}^{+}}\right) \text {(Benefit criteria) } \\
r_{i j} & =\left(\frac{a_{j}^{-}}{c_{i j}}, \frac{a_{j}^{-}}{b_{i j}}, \frac{a_{j}^{-}}{a_{i j}}\right) \text { (Cost criteria) }
\end{aligned}
$$

where $c_{j}^{+}=\max \left\{c_{i j}\right\}$ for benefit criteria and $a_{j}{ }^{-}=\min \left\{a_{i j}\right\}$ for cost criteria.

In this study, the benefit criteria were adopted when the candidate's interest is to obtain the highest score to be considered the best option. Similarly, the cost criteria were adopted when the candidate's interest is to obtain the lowest score to represent the most interesting solution. According to Chen [66], the normalization method mentioned above is to "preserve the property that the ranges of normalized triangular fuzzy numbers belong to $(0 ; 1)$ ".

Step 2: construction of the weighted normalized fuzzy decision matrix

The weighted normalized decision matrix can be calculated by:

$$
V=\left[v_{i j}\right]_{m * n^{\prime}} \quad i=1,2, \ldots, m ; \quad j=1,2, \ldots, n
$$


where $v_{i j}=r_{i j} \times w_{j}$ and $w_{j}$ is the weight of the $j$ th attribute.

Step 3: definition of the fuzzy positive ideal solution (FPIS, $A+$ ) and fuzzy negative ideal solution (FNIS, $A-$ )

$$
\begin{array}{ll}
A^{+}=\left(v_{1}^{+},\right. & \left.v_{2}^{+}, \ldots, v_{n}^{+}\right) \\
A^{-}=\left(v_{1}^{-},\right. & \left.v_{2}^{-}, \ldots, v_{n}^{-}\right)
\end{array}
$$

where $v_{j}^{+}=(1 ; 1 ; 1)$ and $v_{j}^{-}=(0 ; 0 ; 0), j=1,2, \ldots, n$.

Step 4: calculation of the distance of each alternative from $A+\left(d_{i}^{+}\right)$and $A-\left(d_{i}^{-}\right)$, respectively.

$$
\begin{aligned}
& d_{i}^{+}=\sum_{j=1}^{n} d\left(v_{i j}, v_{j}^{+}\right), \quad i=1,2, \ldots, m \\
& d_{i}^{-}=\sum_{j=1}^{n} d\left(v_{i j}, v_{j}^{-}\right), \quad i=1,2, \ldots, m
\end{aligned}
$$

where $d(A, B)$ is the distance measurement between two fuzzy triangular numbers, $A=\left(a_{1}, b_{1}, c_{1}\right)$ and $B=\left(a_{2}, b_{2}, c_{2}\right)$, and is calculated as:

$$
d(A, B)=\sqrt{\frac{1}{3}\left[\left(a_{1}-a_{2}\right)^{2}+\left(b_{1}-b_{2}\right)^{2}+\left(c_{1}-c_{2}\right)^{2}\right]}
$$

Step 5: calculation of the closeness coefficient (CCi) of each alternative

$$
C C_{i}=\frac{d_{i}^{-}}{d_{i}^{+}+d_{i}^{-}}, \quad i=1,2, \ldots, m
$$

Step 6: ranking of alternatives

The alternatives are ranked with respect to the $C C i$ in decreasing order. The best alternative is closer to $A+$ as $C C i$ approaches 1 [66].

This approach was proposed by Chen [66] and stands out for being one of the most applied in decision problems related to supplier selection $[4,33]$. The mathematical equations employed were operationalized through computational simulations in MATLAB ${ }^{\circledR}$.

\subsection{Linguistic Variables}

FTOPSIS application requires a scale of linguistic terms to be defined to assess the level of importance of the criteria, thus allowing the evaluation of suppliers' performance. This study adopted a five-point linguistic scale to be applied during the experts' judgment, ranging from very low (VL), which refers to poor quality and the ability of the supplier to perform a service, to very high $(\mathrm{VH})$, which should be attributed to the best possible performance within the evaluated problem. The set of linguistic terms in Table 1 is recommended for use in fuzzy-TOPSIS models applied to supplier selection, in which the values of $a, b$, and $c$ represent crisp numbers of an evaluation scale.

Table 1. Set of linguistic terms used in FTOPSIS.

\begin{tabular}{cccccc}
\hline Linguistic Term & Very Low $(\mathrm{VL})$ & $\begin{array}{c}\text { Low } \\
(\mathbf{L})\end{array}$ & $\begin{array}{c}\text { Medium } \\
(\mathbf{M})\end{array}$ & $\begin{array}{c}\text { High } \\
(\mathbf{H})\end{array}$ & Very High (VH) \\
\hline Valor fuzzy & $\left(a_{\mathrm{VL}}, b_{\mathrm{VL}}, c_{\mathrm{VL}}\right)$ & $\left(a_{\mathrm{L}}, b_{\mathrm{L}}, c_{\mathrm{L}}\right)$ & $\left(a_{\mathrm{M}}, b_{\mathrm{M}}, c_{\mathrm{M}}\right)$ & $\left(a_{\mathrm{H}}, b_{\mathrm{H}}, c_{\mathrm{H}}\right)$ & $\left(a_{\mathrm{VH}}, b_{\mathrm{VH}}, c_{\mathrm{VH}}\right)$ \\
\hline
\end{tabular}

After defining a set of linguistic variables, fuzzy values should be attributed to the proper linguistic term scale. Thus, such terms should be modeled using triangular functions, as this function is most appropriate to this kind of problem, according to Chen [66], as presented in Table 2. 
Table 2. Fuzzy number scale for level of importance (weight) of decision criteria and performance evaluation of criteria.

\begin{tabular}{ccc}
\hline Linguistic Term & Fuzzy Values for Criteria Weight & Fuzzy Values for Performance Evaluation \\
\hline Very Low (VL) & $(0.0,0.0,0.25)$ & $(0.0,0.0,2.5)$ \\
Low (L) & $(0.0,0.25,0.50)$ & $(0.0,2.5,5.0)$ \\
Medium (M) & $(0.25,0.50,0.75)$ & $(2.5,5.0,7.5)$ \\
High (H) & $(0.50,0.75,1.0)$ & $(5.0,7.5,10)$ \\
Very High (VH) & $(0.75,1.0,1.0)$ & $(7.5,10,10)$ \\
\hline
\end{tabular}

\subsection{HSE Criteria Definition}

The definition of the decision criteria related to HSE must consider the requirements and policies of the organization responsible for the bidding process. These criteria should reflect the organization's HSE management priorities and consider the operational risk within the scope of service to be performed. In the TOPSIS method, a common practice is to use only the interviewee's perception and experience to assess without requiring any data. However, in applying the FTOPSIS method, it is suggested to associate predefined linguistic terms with qualitative and quantitative scales to drive the performance evaluation of each criterion. A set of four HSE criteria were considered, which are detailed below:

- (C1) Accident History

$\mathrm{C} 1$ is defined based on accident statistics with damage to workers' integrity, where events with minor or severe injuries, restricted work, lost time, and fatalities should be considered. The reference scale is defined in Table 3. According to the Occupational Safety and Health Administration (OSHA), it is directly related to the total recordable case frequency (TRCF), which refers to the total number of accidents recorded for one million hours worked, according to the Occupational Safety and Health Administration (OSHA). It is suggested to consider the accumulated TRCF in the last three years of the supplier's operations at a global level.

Table 3. Accident history (C1) rating scale.

\begin{tabular}{ccc}
\hline & Linguistic Term & Rating Scale \\
\cline { 2 - 3 } & Very Low $(\mathrm{VL})$ & Non-applicable \\
Low $(\mathrm{L})$ & $\mathrm{TRCF}>5$ \\
& Medium $(\mathrm{M})$ & $2<\mathrm{TRCF} \leq 5$ \\
High $(\mathrm{H})$ & $0<\mathrm{TRCF} \leq 2$ \\
& Very High $(\mathrm{VH})$ & $\mathrm{TRCF}=0$ \\
\hline
\end{tabular}

- (C2) Management System

C2 must reflect the quality of the HSE integrated management system (IMS) implemented by the contractor to manage client operations. The reference scale is defined in Table 4.

Table 4. Management system (C2) rating scale.

\begin{tabular}{|c|c|c|}
\hline \multirow{6}{*}{ 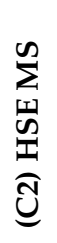 } & Linguistic Term & Rating Scale \\
\hline & Very Low (VL) & HSE MS not implemented \\
\hline & Low $(\mathrm{L})$ & HSE MS implemented with critical gaps \\
\hline & Medium (M) & HSE MS implemented with medium gaps \\
\hline & $\operatorname{High}(\mathrm{H})$ & HSE MS implemented with slight opportunities of improvement \\
\hline & Very High (VH) & HSE MS fully implemented \\
\hline
\end{tabular}

- (C3) Plans and Procedures 
This criterion refers to the quality of operational procedures and plans required for HSE management during the execution of the activity within the scope of O\&M services. The reference scale is defined in Table 5.

Table 5. Plans and procedures (C3) rating scale.

\begin{tabular}{ccc}
\hline & Linguistic Term & Rating Scale \\
\cline { 2 - 3 } & Very Low $(\mathrm{VL})$ & Non-existing plans and procedures \\
Low $(\mathrm{L})$ & Plans and procedures with critical gaps \\
& Medium $(\mathrm{M})$ & Plans and procedures with medium gaps \\
High $(\mathrm{H})$ & Plans and procedures implemented with slight \\
& Very High $(\mathrm{VH})$ & Plans and procedures fully implemented \\
\hline
\end{tabular}

\section{- (C4) Scope Specifics}

This indicator refers to a specific criterion related to the scope of work. It will assess the supplier's ability concerning specific aspects related to the scope of the services, to be defined according to the level of operational risk involved. This can result from a new regulation or operational requirement related to the HSE performance of the project.

\section{Results}

\subsection{Problem Dimension}

The problem related to supplier selection presented in this hypothetical case study is based on an oil and gas company, whose main activity is within Deepwater exploration and production. This company is developing a new field, and a contract is being bid for the floating production storage and offloading unit (FPSO) operations, which will be operated during the production phase. In the oil and gas industry, this contract category is well known as an operation and maintenance (O\&M) contract, which is defined as an agreement where the contracting company transfers the asset management and full responsibility for the plant operations and maintenance to the contractor.

The complexity inherent to this type of contract, related to operational interfaces and long-term contracts, must be considered. Therefore, companies contracted to operate in the scope of O\&M must be highly qualified for this purpose. Failures in an O\&M contract can compromise the customer's reputation and cause significant economic losses, undesirable occupational safety events, and great damage to the environment.

In this case study, three companies were competing in the bidding process, of which one of them should be selected as the most qualified supplier to execute the O\&M contract from an HSE standpoint. Such companies should be evaluated against four decision criteria, which reflected the HSE standards of the oil and gas industry. The assessment should be performed by the company HSE specialist, based on the questionnaire answered by the suppliers, and submitted within the bidding supporting documentation.

The application of the FTOPSIS model necessarily depends on the evaluation of the weights of each decision criterion. A single value must be assigned to each criterion, according to the linguistic terms scale defined in Section 3. However, in order to better reflect the operational risk related to the scope of the service to be hired, it is suggested that this weight assessment is related to the degree of risk involved. Determining the degree of risk related to the scope of a given activity can be performed using a qualitative methodology of preliminary risk analysis. A conventional risk matrix correlates an event occurrence probability with the impact of its consequence to define the activity's degree of risk, i.e., high, medium, or low [67].

A risk matrix can be presented in different formats, which may vary according to the adopted methodology, but are usually composed of a vertical and a horizontal axis. The first corresponds to the degree of risk severity and second to the probability of its occurrence. In this paper, a risk matrix model adapted from an existing methodology of an oil and gas company was adopted. The model has six severity scale levels, ranging from 
0 to 5 , and five probability scale levels, ranging from " $\mathrm{A}$ " to " $\mathrm{E}$," according to Figure 2. These scales should be adjusted according to the particularities of each organization, but an interesting practice is to associate qualitative and quantitative scales with determining the severity and probability levels.

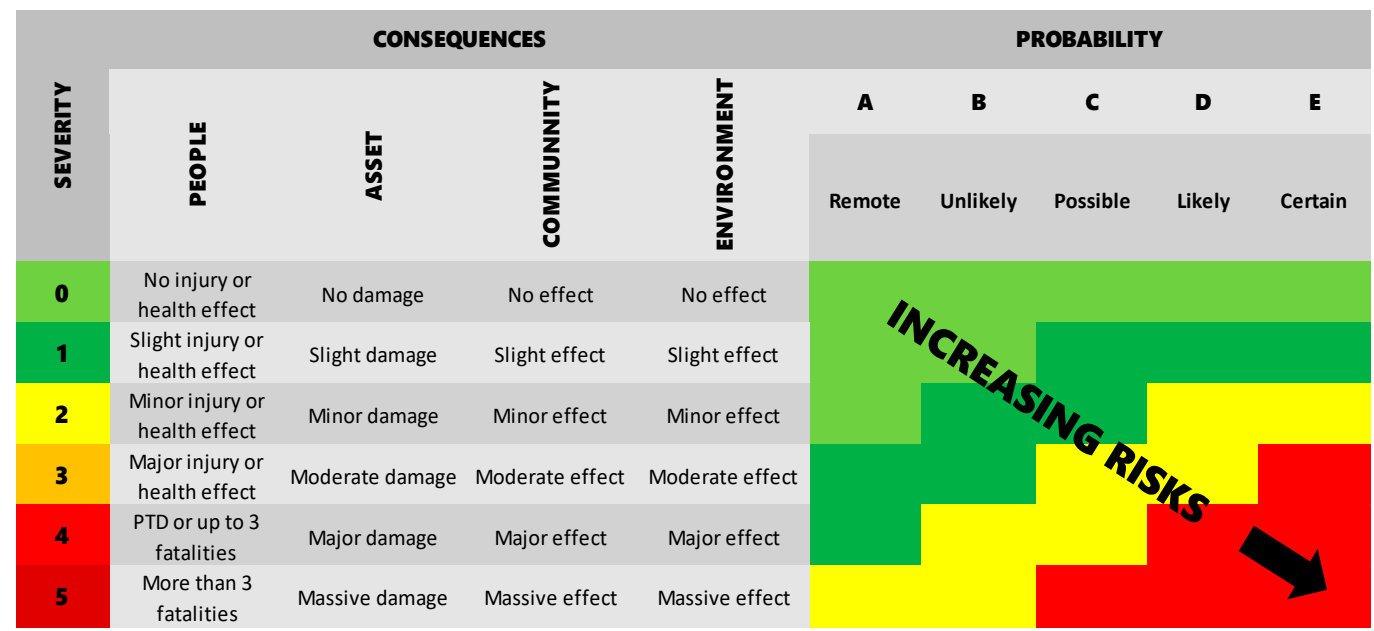

PTD = permanent total disability

Figure 2. Risk assessment matrix.

Based on the defined degree of risk, it was possible to suggest the levels of importance (weights) to be attributed for each decision criterion adopted in the supplier selection problem, as presented in Table 6. It is important to explain that, for this case study, C4 was defined to be the compliance with local regulatory requirements regarding the learnings from a relevant process incident involving an FPSO operated in Brazil.

Table 6. Correlation between the operation risk level and the level of importance of each decision criterion.

\begin{tabular}{cccc}
\hline Level of Risk & Low & Medium & High \\
\hline Decision Criteria & & Level of Importance (Weight) & Very High (VH) \\
(C1) Accident History & Medium (M) & High (H) & High (H) \\
(C2) HSE MS & Low (L) & Medium (M) & Very High (VH) \\
(C3) Plans and Procedures & Medium (M) & High (H) & High (H) \\
(C4) Scope Specifics & Low (L) & Medium (M) & \\
\hline
\end{tabular}

Since the scope of O\&M is characterized for its operational complexity, requiring high-capacity contractors due to the potential consequences of undesirable events, it can be considered as a "high" risk scope according to the risk matrix.

\subsection{Results of Model Implementation}

The three competing suppliers $\left(\mathrm{S}_{1}, \mathrm{~S}_{2}\right.$, and $\left.\mathrm{S}_{3}\right)$ were evaluated by the HSE specialist, illustrated in Table 7, considering the criteria weights of the decision criteria for a high operational risk scope. The assessment was made based on expert judgment, assigning a unique linguistic value to reflect the supplier's performance on each criterion, based on supporting documentation submitted by each supplier as part of the bidding documentation. 
Table 7. Supplier performance evaluation.

\begin{tabular}{ccccc}
\hline Criteria & $\mathrm{S}_{\mathbf{1}}$ & $\mathrm{S}_{\mathbf{2}}$ & $\mathrm{S}_{\mathbf{3}}$ & Criteria Weight \\
\hline (C1) Accident History & $\mathrm{H}$ & $\mathrm{M}$ & $\mathrm{L}$ & $\mathrm{VH}$ \\
(C2) HSE MS & $\mathrm{M}$ & $\mathrm{H}$ & $\mathrm{M}$ & $\mathrm{H}$ \\
(C3) Plans and Procedures & $\mathrm{M}$ & $\mathrm{H}$ & $\mathrm{M}$ & $\mathrm{VH}$ \\
(C4) Scope Specific & $\mathrm{M}$ & $\mathrm{M}$ & $\mathrm{L}$ & $\mathrm{H}$ \\
\hline
\end{tabular}
Source: Research data.

Linguistic values attributed by the specialist were then replaced by corresponding fuzzy numbers (Table 8), according to the triangular function defined in Section 3.

Table 8. Fuzzy numbers attributed to each supplier evaluation.

\begin{tabular}{ccccc}
\hline Criteria & $\mathbf{S}_{\mathbf{1}}$ & $\mathbf{S}_{\mathbf{2}}$ & $\mathbf{S}_{\mathbf{3}}$ & Criteria Weight \\
\hline$(\mathrm{C} 1)$ & $(5.0,7.5,10.0)$ & $(2.5,5.0,7.5)$ & $(0.0,2.5,5.0)$ & $(0.75,1.0,1.0)$ \\
$(\mathrm{C} 2)$ & $(2.5,5.0,7.5)$ & $(5.0,7.5,10.0)$ & $(2.5,5.0,7.5)$ & $(0.50,0.75,1.0)$ \\
$(\mathrm{C} 3)$ & $(2.5,5.0,7.5)$ & $(5.0,7.5,10.0)$ & $(2.5,5.0,7.5)$ & $(0.75,1.0,1.0)$ \\
$(\mathrm{C} 4)$ & $(2.5,5.0,7.5)$ & $(2.5,5.0,7.5)$ & $(0.0,2.5,5.0)$ & $(0.50,0.75,1.0)$ \\
\hline
\end{tabular}

After judging all the alternatives in light of each decision criterion, the evaluations were processed through MATLAB ${ }^{\circledR}$. The main function was used to define the parameters of some alternatives, criteria, experts interviewed, as well as to import data of the evaluations on the alternative's performance on each decision criterion. Two subfunctions associated with the main function were applied to aggregate and fuzzify the parameters of supplier's performance and the decision criteria weights. Another function was defined for calculating the output parameters of the fuzzy-TOPSIS model, i.e., positive and negative ideal solutions (FPIS and FNIS), distance between solutions $\left(d^{+}\right.$and $\left.d^{-}\right)$, closeness coefficient, and the final ranking of supplier alternatives.

Before calculating the output parameters, it was necessary to apply a weighting and normalization subfunction to the performance and weights databases. The weighted matrix is the products of multiplying the triangular functions, representing the performance of each alternative, by the triangular functions representing the weight of each criterion evaluated, while the normalized matrix consists of the standardization of the performance matrix elements. The results of the operations obtained by applying each function in MATLAB $^{\circledR}$ are presented in Tables 9-12.

Table 9. Weighted and normalized supplier performance matrix.

\begin{tabular}{cccc}
\hline Criteria & $\mathbf{S}_{\mathbf{1}}$ & $\mathbf{S}_{\mathbf{2}}$ & $\mathbf{S}_{\mathbf{3}}$ \\
\hline$(\mathrm{C} 1)$ & $(0.375,0.75,1.0)$ & $(0.1875,0.50,0.75)$ & $(0.0,0.25,0.50)$ \\
$(\mathrm{C} 2)$ & $(0.125,0.375,0.75)$ & $(0.25,0.5625,1.0)$ & $(0.125,0.375,0.75)$ \\
$(\mathrm{C} 3)$ & $(0.1875,0.50,0.75)$ & $(0.375,0.75,1.0)$ & $(0.1875,0.50,0.75)$ \\
$(\mathrm{C} 4)$ & $(0.125,0.375,0.75)$ & $(0.125,0.375,0.75)$ & $(0.0,0.1875,0.50)$ \\
\hline
\end{tabular}

Source: MATLAB ${ }^{\circledR}$.

Table 10. Distance between alternatives from FPIS.

\begin{tabular}{ccccc}
\hline & $\mathbf{( C 1 )}$ & $\mathbf{( C 2 )}$ & $\mathbf{( C 3 )}$ & (C4) \\
\hline$d\left(\mathrm{~F}_{1}, d^{+}\right)$ & 0.388641 & 0.637377 & 0.569402 & 0.637377 \\
$d\left(\mathrm{~F}_{2}, d^{+}\right)$ & 0.569402 & 0.5013 & 0.388641 & 0.637377 \\
$d\left(\mathrm{~F}_{3}, d^{+}\right)$ & 0.777282 & 0.637377 & 0.569402 & 0.797947 \\
\hline
\end{tabular}


Table 11. Distance between alternatives from FNIS.

\begin{tabular}{lcccc}
\hline & (C1) & (C2) & (C3) & (C4) \\
\hline$d\left(\mathrm{~F}_{1}, d^{-}\right)$ & 0.753464 & 0.489473 & 0.531556 & 0.489473 \\
$d\left(\mathrm{~F}_{2}, d^{-}\right)$ & 0.531556 & 0.677964 & 0.753464 & 0.489473 \\
$d\left(\mathrm{~F}_{3}, d^{-}\right)$ & 0.322749 & 0.489473 & 0.531556 & 0.308305 \\
\hline
\end{tabular}

Source: MATLAB ${ }^{\circledR}$.

Table 12. Closeness coefficient (CCi).

\begin{tabular}{cccc}
\hline & $\mathbf{F}_{\mathbf{1}}$ & $\mathbf{F}_{\mathbf{2}}$ & $\mathbf{F}_{\mathbf{3}}$ \\
\hline$d^{+}$ & 1.746101 & 1.544556 & 1.926862 \\
$d^{-}$ & 1.673268 & 1.918262 & 1.45136 \\
$C C i$ & 0.4894 & 0.5540 & 0.4296 \\
\hline
\end{tabular}

Source: MATLAB ${ }^{\circledR}$.

Closeness coefficient values were ranked in a way that the highest preference is equivalent to the supplier with a $C C i$ value closer to 1 , and the lowest preference is equivalent to the $C C i$ closer to 0 . The result of the fuzzy-TOPSIS ranking is equal to $S_{2}>S_{1}>S_{3}$. Therefore, supplier $S_{2}$ should be considered the best alternative among the set of suppliers evaluated in this problem since the closeness coefficient value is closest to the ideal solution value (1.0), as demonstrated in Table 13 below.

Table 13. Final ranking.

\begin{tabular}{ccc}
\hline Order & Supplier & CCi \\
\hline $1^{\circ}$ & $\mathrm{S}_{2}$ & 0.5540 \\
$2^{\circ}$ & $\mathrm{S}_{1}$ & 0.4894 \\
$3^{\circ}$ & $\mathrm{S}_{3}$ & 0.4296 \\
\hline
\end{tabular}

Source: MATLAB ${ }^{\circledR}$.

\section{Discussion and Conclusions}

The fuzzy-TOPSIS model for supplier selection with a focus on HSE aspects was applied considering four decision criteria. Each criterion was defined based on oil and gas industry standards for HSE management. For each of them, qualitative and quantitative scales were attributed to guide the logical reasoning in the alternative's evaluation in each criterion. Thus, the evaluation was performed by only one specialist since it was based on well-defined qualitative and quantitative foundations. Then, it is fair to say that the judgment of the supplier's performance did not depend only on the perception or opinion of a group of experts but also on data and facts verified through documents submitted during the tendering process.

On the other hand, the level of importance attributed to each criterion was defined based on the risk analysis of the operational scope to be performed, based on the exposure involved in offshore FPSO O\&M activities. The level of risk was determined through a reference matrix and defined as high. Each criterion was weighted using a scale of previously described linguistic variables. However, there is some subjectivity involved in this process since there is no quantitative correlation between the level of risk and the weights attributed to the decision criteria, which was based only on the qualitative judgment of the specialist responsible for applying the method.

The computational simulation step was implemented in MATLAB ${ }^{\circledR}$. Different blocks of programming functions were used and proved to be suitable for this kind of problem, with good user experience and low computational complexity, allowing a simple implementation of the FTOPSIS model.

From the results found, it can be stated that the application of the fuzzy-TOPSIS model is suitable for supplier selection problems, especially in the final stage. Some of the benefits of applying this method are: 
- Allowing to attribute weights according to the level of importance of each criterion;

- Considers the complexity, subjectivity, and uncertainty of the decision process.

As an FTOPSIS model result in the case study, the higher value of CCi was obtained for supplier $S_{2}$, and a lower value of CCi was obtained for $S_{1}$ and $S_{3}$, respectively. Additionally, based on the judgment of each supplier's performance, there is evidence that the final ranking order obtained by the FTOPSIS method is correct, given that, based on the expert's experience and the assigned linguistic values, supplier $\mathrm{S}_{2}$ was expected to have better performance than suppliers $S_{1}$ and $S_{3}$.

Therefore, the importance of having a robust and consistent process for weighting the criteria and defining the most appropriate linguistic variables was clear. The results obtained in this paper reinforce the infinite possibilities that fuzzy sets have in representing and capturing the uncertainties and subjectivity inherent to supplier selection problems. It is noticeable that the application of the fuzzy-TOPSIS method by itself does not guarantee the ability of a supplier to safely execute and manage the risks of a given scope. However, it is highly recommended that a deeper and detailed assessment should be performed under the selected alternative to identify improvement opportunities and address the main gaps of the supplier regarding its HSE management system, so that these points are continuously addressed under the contract, before and after activities and according to the operational risk involved.

Although MCDM models integrated with fuzzy logic can effectively handle uncertainties of the decision-making process, this research is subjected to some limitations that should be considered, and some may serve as a stimulus for future work. First, this study considered the assessment of a single specialist, which rarely occurs in practice, as this important decision is usually taken by more than one DM. Second, four criteria are not enough to cover all aspects of HSE needed for reliable decision making, given its complexity and relevance. Third, once the most relevant safety criteria have been defined, several methods can be applied to rank the best suppliers. Thus, the use of other MCDM models is encouraged to investigate which one best fits the criteria in question. The combination of MCDM techniques with non-parametric methods such as DEA can also bring benefits to this type of research, as it allows the efficiency analysis of the options from multiple inputs and outputs. Therefore, current research can be extended in several directions to approaches the methodology to real-life supplier selection problems. The use of new techniques to establish the weight of each criterion based on each specialist's experience and expand the number of criteria to be evaluated should be incorporated in future work.

Author Contributions: Conceptualization, A.N.H. and L.S.d.A.; methodology, A.N.H. and L.S.d.A.; software, L.S.d.A.; validation, A.N.H., A.H., and B.B.F.d.C.; formal analysis, C.A.P.S.; investigation, B.B.F.d.C.; resources, B.B.F.d.C.; data curation, B.B.F.d.C.; writing—original draft preparation, L.S.d.A. and B.B.F.d.C.; writing-review and editing, B.B.F.d.C., A.H., and C.A.P.S.; visualization, B.B.F.d.C.; supervision, A.N.H.; project administration, A.N.H.; funding acquisition, A.N.H. All authors have read and agreed to the published version of the manuscript.

Funding: This research received no external funding.

Data Availability Statement: Data will be available upon reasonable request.

Acknowledgments: The financial support of CAPES (Coordenação de Aperfeiçoamento de Pessoal de Nível Superior), Brasilia, DF, Brasil, CNPq (Conselho Nacional de Desenvolvimento Científico e Tecnológico), formerly Conselho Nacional de Pesquisas, Brasilia, DF, Brasil (the Brazilian National Research Council), and Fundação Carlos Chagas Filho de Amparo à Pesquisa do Estado do Rio de Janeiro (FAPERJ) in pursuit of this work are gratefully acknowledged.

Conflicts of Interest: The authors declare no conflict of interest. 


\section{References}

1. Katopodis, T.; Sfetsos, A. A review of climate change impacts to oil sector critical services and suggested recommendations for industry uptake. Infrastructures 2019, 4, 74. [CrossRef]

2. Ventura, J.A.; Bunn, K.A.; Venegas, B.B.; Duan, L. A coordination mechanism for supplier selection and order quantity allocation with price-sensitive demand and finite production rates. Int. J. Produc. Econ. 2021, 233, 108007. [CrossRef]

3. Smith, G.W. Contractor Safety Management, 1st ed.; CRC Press: Boca Raton, FL, USA, 2013.

4. Mina, H.; Kannan, D.; Gholami-Zanjani, S.M.; Biuki, M. Transition towards circular supplier selection in petrochemical industry: A hybrid approach to achieve sustainable development goals. J. Clean. Prod. 2021, 286, 125273. [CrossRef]

5. Haeri, S.A.S.; Rezaei, J. A grey-based green supplier selection model for uncertain environments. J. Clean. Prod. 2019, 221, 768-784. [CrossRef]

6. Hollnagel, E.; Woods, D.D.; Leveson, N. Resilience Engineering: Concepts and Precepts, 1st ed.; CRC Press: Boca Raton, FL, USA, 2006.

7. Rashvand, P.; Majid, M.Z.A.; Pinto, J.K. Contractor management performance evaluation model at prequalification stage. Expert Syst. Appl. 2015, 42, 5087-5101. [CrossRef]

8. Ahmadi, H.B.; Lo, H.; Gupta, H.; Kusi-Sarpong, S.; Liou, J.J.H. An integrated model for selecting suppliers on the basis of sustainability innovation. J. Clean. Prod. 2020, 277, 123261. [CrossRef]

9. Memari, A.; Dargi, A.; Jokar, M.R.A.; Ahmad, R.; Rahim, A.R.A. Sustainable supplier selection: A multicriteria intuistionistic fuzzy TOPSIS method. J. Manuf. Syst. 2019, 50, 9-24. [CrossRef]

10. Jain, N.; Singh, A.R. Sustainable supplier selection under must-be criteria through fuzzy inference system. J. Clean. Prod. 2020, 248, 119275. [CrossRef]

11. Taherdoost, H.; Brard, A. Analyzing the process of supplier selection criteria and methods. Proced. Manufac. 2019, 32, 1024-1034. [CrossRef]

12. Qu, G.; Zhang, Z.; Qu, W.; Xu, Z. Green supplier selection based on green practices evaluated using fuzzy approaches of TOPSIS and ELECTRE with a case study in a chinese internet company. Int. J. Environ. Res. Public Health 2020, 17, 3268. [CrossRef]

13. Okwu, M.O.; Tartibu, L.K. Sustainable supplier selection in the retail industry: A TOPSIS- and ANFIS-based evaluating methodology. Int. J. Eng. Bus. Manag. 2020, 12, 1-14. [CrossRef]

14. Gunasekaran, A.; Patel, C.; McGaughey, R.E. A framework for supply chain performance measurement. Int. J. Prod. Econ. 2004, 87, 333-347. [CrossRef]

15. Ramakrishnan, K.R.; Chakraborty, S. A cloud TOPSIS model for green supplier selection. Facta Univ. 2020, 18, 375-397. [CrossRef]

16. Chang, T.; Pai, C.; Lo, H.; Hu, S. A hybrid decision-making model for sustainable supplier evaluation in electronics manufacturing. Comput. Ind. Eng. 2021, 156, 107283. [CrossRef]

17. Feng, J.; Gong, Z. Integrated linguistic entropy weight method and multi-objective programming model for supplier selection and order allocation in a circular economy: A case study. J. Clean. Prod. 2020, 277, 122597. [CrossRef]

18. Xian, S.; Guo, H. Novel supplier grading approach based on interval probability hesitant fuzzy linguistic TOPSIS. Eng. Applic. Artif. Intellig. 2020, 87, 103299. [CrossRef]

19. Gupta, S.; Soni, U.; Kumar, G. Green supplier selection using multi-criterion decision making under fuzzy environment: A case study in automotive industry. Comput. Ind. Eng. 2019, 136, 663-680. [CrossRef]

20. Yu, C.; Shao, Y.; Wang, K.; Zhang, L. A group decision making sustainable supplier selection approach using extended TOPSIS under interval-valued Pythagorean fuzzy environment. Expert Syst. Appl. 2019, 121, 1-17. [CrossRef]

21. Patil, A.N.; Shivkumar, K.M.; Patel, M.; Jatti, S.P.; Rivankar, S.N. Fuzzy TOPSIS and grey relation analysis integration for supplier selection in fiber industry. Int. J. Supply Oper. Manag. 2020, 7, 373-383.

22. Liu, A.; Xiao, Y.; Lu, H.; Tsai, S.; Song, W. A fuzzy three-stage multi-attribute decision-making approach based on customer needs for sustainable supplier selection. J. Clean. Prod. 2019, 239, 118043. [CrossRef]

23. Wang, C.; Tsai, H.; Nguyen, V.T.; Nguyen, V.T.; Huang, Y. A hybrid fuzzy analytic hierarchy process and the technique for order of preference by similarity to ideal solution supplier evaluation and selection in the food processing industry. Symmetry 2020, 12, 211. [CrossRef]

24. Chen, C. A novel multicriteria decision-making model for building material supplier selection based on Entropy-AHP weighted TOPSIS. Entropy 2020, 22, 259. [CrossRef]

25. Ho, W.; Xu, X.; Dey, P.K. Multi-criteria decision making approaches for supplier evaluation and selection: A literature review. Eur. J. Oper. Res. 2010, 202, 16-24. [CrossRef]

26. Luthra, S.; Govindan, K.; Kannan, D.; Mangla, S.K.; Garg, C.P. An integrated framework for sustainable supplier selection and evaluation in supply chains. J. Clean. Prod. 2017, 140, 1686-1698. [CrossRef]

27. Qazvini, Z.E.; Haji, A.; Mina, H. A fuzzy solution approach to supplier selection and order allocation in green supply chain considering the location-routing problem. Scientia Iranica 2021, 28, 446-464. [CrossRef]

28. Stevic, Z.; Pamucar, D.; Puska, A.; Chatterjee, P. Sustainable supplier selection in healthcare industries using a new MCDM method: Measurement of alternatives and ranking according to compromise solution (MARCOS). Comput. Ind. Eng. 2020, 140, 106231. [CrossRef]

29. Rashidi, K.; Cullinane, K. A comparison of fuzzy DEA and fuzzy TOPSIS in sustainable supplier selection: Implications for sourcing strategy. Expert Syst. Appl. 2019, 121, 266-281. [CrossRef] 
30. Chen, Z.; Ming, X.; Zhou, T.; Chang, Y. Sustainable supplier selection for smart supply chain considering internal and external uncertainty: An integrated rough-fuzzy approach. Appl. Soft. Comput. 2020, 87, 106004. [CrossRef]

31. Nasr, A.K.; Tavana, M.; Alavi, B.; Mina, H. A novel fuzzy multi-objective circular supplier selection and order allocation model for sustainable closed-loop supply chains. J. Clean. Prod. 2021, 287, 124994. [CrossRef]

32. Hoseini, S.A.; Fallahpour, A.; Wong, K.Y.; Mahdiyar, A.; Saberi, M.; Durdyev, S. Sustainable supplier selection in construction industry through hybrid fuzzy-based approaches. Sustainability 2021, 13, 1413. [CrossRef]

33. Sureeyatanapas, P.; Waleekhajornlert, N.; Arunyanart, S.; Niyamosoth, T. Resilient supplier selection in electronic components procurement: An integration of evidence theory and rule-based transformation into TOPSIS to tackle uncertain and incomplete information. Symmetry 2020, 12, 1109. [CrossRef]

34. Bazrafshan, R.; Zolfani, A.H.; Al-e-hashem, M.J.M. Comparison of the sub-tour elimination methods for the asymmetric traveling salesman problem applying the SECA method. Axioms 2021, 10, 19. [CrossRef]

35. Keshavarz-Ghorabaee, M.; Amiri, M.; Hashemi-Tabatabaei, M.; Zavadskas, E.K.; Kaklauskas, A. A new decision-making aprroach based on fermatean fuzzy sets and WASPAS for green construction supplier selection. Mathematics 2020, 8, 2202. [CrossRef]

36. Torkayesh, S.E.; Iranizad, A.; Torkayesh, A.E.; Basit, M.N. Application of BWM-WASPAS model for digital supplier selection problem: A case study in online retail shopping. J. Indust. Eng. Decis. Mak. 2020, 1, 12-23. [CrossRef]

37. Xu, D.; Cui, X.; Xian, H. An extended EDAS method with a single-valued complex neutrosophic set and its application in green supplier selection. Mathematics 2020, 8, 282. [CrossRef]

38. We, G.; Wei, C.; Guo, Y. EDAS method for probabilistic linguistic multiple attribute group decision making and their application to green supplier selection. Soft Comput. 2021, 25, 9045-9053. [CrossRef]

39. Puska, A.; Nedeljkovic, M.; Zolfani, S.H.; Pamucar, D. Application of interval fuzzy logic in selecting a sustainable supplier on the example of agricultural production. Symmetry 2021, 13, 774. [CrossRef]

40. Jovcic, S.; Simic, V.; Prusa, P.; Dobrodolac, M. Picture fuzzy ARAS method for freight distribution concept selection. Symmetry 2020, 12, 1062. [CrossRef]

41. Fu, Y.; Wy, C.; Lia, C. Selection of in-flight duty-free product suppliers using a combination fuzzy AHP, fuzzy ARAS, and MSGP methods. Mathem. Prob. Eng. 2021, 2021. [CrossRef]

42. Stanujkic, D.; Popovic, G.; Karabasevic, D.; Meidute-Kavaliauskiene, I.; Ulutas, A. An integrated simple weighted sum product method-WISP. IEEE Trans. Eng. Manag. 2021, 1-12. [CrossRef]

43. Ulutas, A.; Stanujkic, D.; Karabasevic, D.; Popovic, G.; Zavadskas, E.K.; Smarandache, F.; Brauers, W.K.M. Developing of a novel integrated MCDM MULTIMOOSRAL approach for supplier selection. Informatica 2021, 32, 145-161. [CrossRef]

44. Abdel-Basset, M.; Mohamed, M.; Smarandache, F. A hybrid neutrosophic group ANP-TOPSIS framework for supplier selection problems. Symmetry 2018, 10, 226. [CrossRef]

45. Azimifard, A.; Moosavirad, S.H.; Ariafar, S. Selecting sustainable supplier countries for Iran's steel industry at three levels by using AHP and TOPSIS method. Resour. Pol. 2018, 57, 30-44. [CrossRef]

46. Wang, C.; Nguyen, N.; Dang, T.; Bayer, J. A two-stage multiple criteria decision making for site selection of solar photovoltaic (PV) power plant: A case study in Taiwan. IEEE Acess 2021, 9, 75509-75525. [CrossRef]

47. Schramm, V.B.; Cabral, L.P.B.; Schramm, F. Approaches for supporting sustainable supplier selection-A literature review. J. Clean. Prod. 2020, 273, 123089. [CrossRef]

48. Mohammed, A.; Setchi, R.; Filip, M.; Harris, I.; Li, X. An integrated methodology for a sustainable two-stage supplier selection and order allocation problem. J. Clean. Prod. 2018, 192, 99-114. [CrossRef]

49. Tirkolaee, E.B.; Mardani, A.; Dashtian, Z.; Soltani, M.; Weber, G. A novel hybrid method using fuzzy decision making and multi-objective programming for sustainable-reliable supplier selection in two-echelon supply chain design. J. Clean. Prod. 2020, 250, 119517. [CrossRef]

50. Li, J.; Fang, H.; Song, W. Sustainable supplier selection based on SSCM practices: A rough cloud TOPSIS approach. J. Clean. Prod. 2019, 222, 606-621. [CrossRef]

51. Kilic, H.S.; Yalcin, A.S. Modified two-phase fuzzy goal programming integrated with IF-TOPSIS for green supplier selection. Appl. Soft. Comput. J. 2020, 93, 106371. [CrossRef]

52. Yu, C.; Chen, K.; Lai, K.; Hsu, C. Fuzzy supplier selection method based on smaller-the-better quality characteristic. Appl. Sci. 2020, 10, 3635. [CrossRef]

53. Zadeh, L.A. Fuzzy sets. Inform. Control 1965, 8, 338-353. [CrossRef]

54. Alavi, B.; Tavana, M.; Mina, H. A dynamic decision support system for sustainable supplier selection in circular economy. Sustain. Prod. Consump. 2021, 27, 905-920. [CrossRef]

55. Sahin, B.; Yip, T.L.; Tseng, P.; Kabak, M.; Soylu, A. An application of a fuzzy TOPSIS multicriteria decision analysis algorithm for dry bulk carrier selection. Information 2020, 11, 251. [CrossRef]

56. Kannan, D.; Mina, H.; Nosrati-Abarghooee, S.; Khosrojerdi, G. Sustainable circular supplier selection: A novel hybrid approach. Sci. Total Environ. 2020, 722, 137936. [CrossRef] [PubMed]

57. Chatterjee, P.; Stevic, Z. A two-phase fuzzy AHP-fuzzy TOPSIS model for supplier evaluation in manufacturing environment. Oper. Res. Eng. Sci. Theory Applic. 2019, 2, 72-90.

58. Hasan, M.M.; Jiang, D.; Ullah, A.M.M.S.; Noor-E-Alam, M. Resilient supplier selection in logistics 4.0 with heterogeneoous information. Expert Syst. Appl. 2020, 139, 112799. [CrossRef] 
59. Javad, M.O.M.; Darvishi, M.; Javad, A.O.M. Green supplier selection for the steel industry using BWM and fuzzy TOPSIS: A case study of Khouzestan steel company. Sustain. Futures 2020, 2, 100012. [CrossRef]

60. Yucesan, M.; Mete, S.; Serin, F.; Celik, E.; Gul, M. An integrated best-worst and interval type-2 fuzzy TOPSIS methodology for green supplier selection. Mathematics 2019, 7, 182. [CrossRef]

61. Kannan, D.; Jabbour, A.B.L.S.; Jabbour, C.J.C. Selecting green suppliers based on GSCM practices: Using fuzzy TOPSIS applied to a Brazilian electronics company. Eur. J. Oper. Res. 2014, 233, 432-447. [CrossRef]

62. Çalik, A. A novel pythagorean fuzzy AHP and fuzzy TOPSIS methodology for green supplier selection in the industry 4.0 era. Soft. Comput. 2021, 25, 2253-2265. [CrossRef]

63. Banaeian, N.; Mobli, H.; Fahimnia, B.; Nielsen, I.E.; Omid, M. Green supplier selection using fuzzy group decision making methods: A case study from the agri-food industry. Comput. Oper. Res. 2018, 89, 337-347. [CrossRef]

64. Hwang, C.L.; Yoon, K. Methods for multiple attribute decision making. In Multiple Attribute Decision Making. Lecture Notes in Economics and Mathematical Systems; Springer: Berlin, Germany, 1981; Volume 186. [CrossRef]

65. Zulqarnain, R.M.; Xin, X.L.; Siddique, I.; Khan, W.A.; Yousif, M.A. TOPSIS method based on correlation coefficient under pythagorean fuzzy soft environment and its application towards green supply chain management. Sustainability 2021, 13, 1642. [CrossRef]

66. Chen, C. Extensions of the TOPSIS for group decision-making under fuzzy environment. Fuzzy Sets Syst. 2000, 114, 1-9. [CrossRef]

67. Pathirana, A.; Radhakrishnan, M.; Bevaart, M.; Voost, E.; Mahasneh, S.; Rob, H.A.A. Fit-for-purpose infrastructure asset management framework for water utilities facing high uncertainties. Infrastructures 2018, 3, 55. [CrossRef] 